\title{
EEG based brain-computer interface control applications: A comprehensive review
}

\author{
Abdullah Bilal Aygun1, Ahmet Resit Kavsaoglu1, Kemal Polat ${ }^{2}$ \\ ${ }^{1}$ Department of Biomedical Engineering, Faculty of Engineering, Karabuk University, Karabuk, Turkey \\ ${ }^{2}$ Department of Electrical and Electronics Engineering, Faculty of Engineering, Bolu Abant Izzet Baysal University, Bolu, \\ Turkey
}

\begin{abstract}
Brain computer interfaces (BCI) is a tool that can make user requests to computerized systems by directly processing brain signals. In order to perform the procedures to be performed, brain signals must be classified. For this purpose, many classification algorithms have been tried with machine learning. The purpose of this study is to talk about both the type of brain signals used in the brain computer interface and the machine learning techniques used in the classification of these signals. In addition, summary information about the classification methods used in brain computer interface control applications in recent years are given in a table.
\end{abstract}

Key words: Brain computer interfaces, EEG, machine learning, classification, mental control signals.

Prof. Dr, Kemal Polat

Department of Electrical and Electronics Engineering, Faculty of Engineering, Bolu Abant Izzet Baysal University, 14280, Bolu, Turkey,

Email: kpolat@ibu.edu.tr

Received: 2021-05-18/Accepted: 2021-05-23

Published online: 2021-06-01

\section{Introduction}

The brain computer interface $(\mathrm{BCI})$ is the system that transforms, develops a system that measures central nervous system (CNS) activity into an artificial output and replaces the ongoing interactions between CNS and the external or internal environment. More simply, a BCI can be defined as a system that converts brain signals into new types of output [1]. The aim is to help people with serious disabilities to live their lives as regularly as possible. Some of these disabilities are classified as neurological neuromuscular disorders [2]. BCI helps neurological patients in daily life, but is generally used for purposes such as: medical, neuro-economic and smart environment, neuromarketing and advertising, education and self-regulation, games and entertainment, and security and authentication [3].

Many operations need to be performed to perform a command with the brain computer interface system. These processes will be mentioned below as articles. But in summary, the working principle of a brain computer interface is as follows in the block diagram in Figure 1: The signals received from the cortex by invasive or non-invasive methods are passed through pretreatments such as amplification and filtering. The signals are then subjected to feature extraction in order to reduce and convert them to data sufficient for classification. The data obtained from here are directed to the classifier according to the classification method whether it is trained or uneducated. In order to realize control in brain computer interfaces, the most accurate classification with the most accurate data is done by classification methods within the scope of machine learning. The purpose of this study is to examine the machine 
learning methods used to classify the EEG signal types used in brain computer interface control applications in the last 5 years. between neurons via electrodes over the scalp $[5,6]$. EEG is a type of biopotential amplifier that transfers the signal received through the

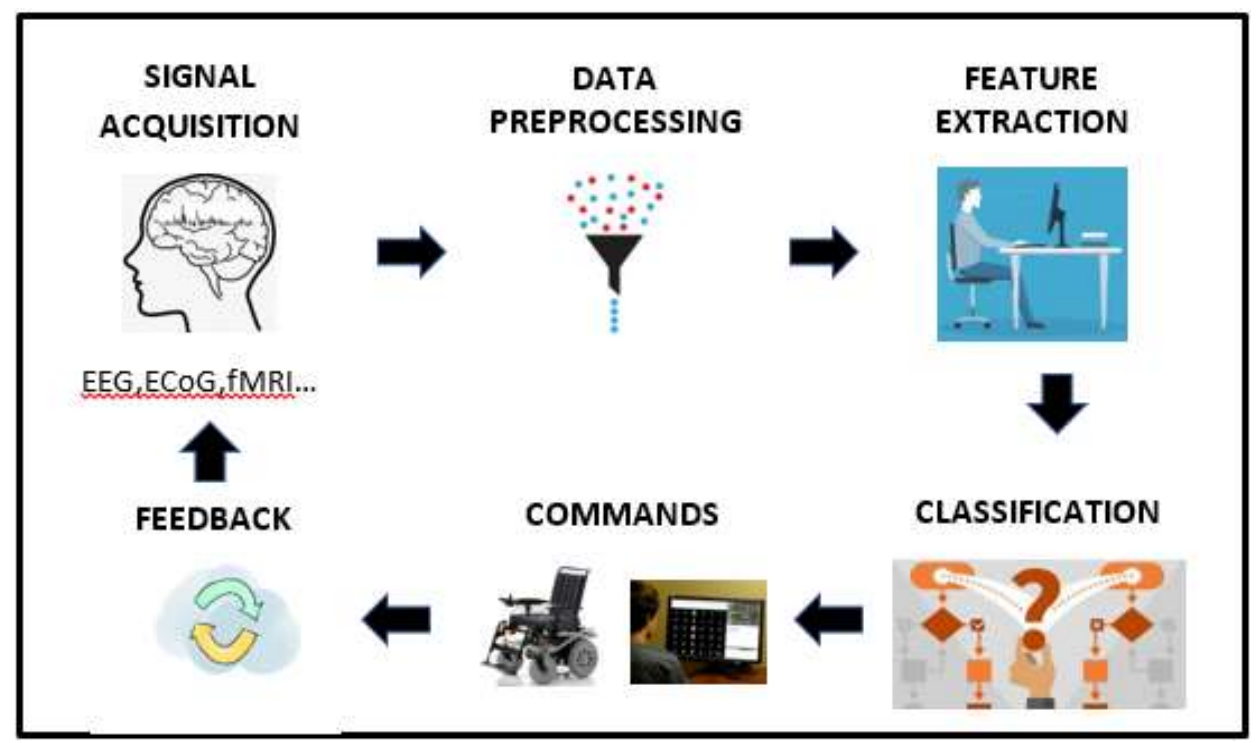

Figure 1. Brain computer interface block diagram.

\section{Signal acquisition}

The first thing to do in brain computer interfaces is to obtain brain signals. Many methods are used for this. These methods can be divided into two groups as generally invasive and non-invasive. Examples of invasive methods are ECoG, microelectrode arrays, while non-invasive methods are EEG, fMRI, fNIRS, MEG. In Table 1, there are signal acquisition methods used in brain computer interface technologies [2], [4].

EEG, which is one of the signal acquisition methods, is the most used method in brain computer interfaces due to its features such that it contains the least risks and difficulties during application due to its non-invasiveness, being more economical and portable than other methods. Therefore, this study focuses only on EEG. A graphic is cited from the work cited in Figure 2 [5].

Electroencephalography is the process of measuring and recording the postsynaptic potentials resulting from ionic activities electrodes to the system output by subjecting it to amplification and filtering [7]. To perform these operations, as shown in the EEG block diagram in Figure 3, the signals received through the electrodes are amplified with the operational amplifier and filtered on the frequency axis, passed through the last amplifier, converted to digital and displayed for analysis according to the new function or directed to the new function.

Electrodes are placed on the scalp according to certain standards. The most common and traditional of these standards is the 10-20 electrode placement system designed by Jasper in 1958. In this form of settlement, the head is marked by four standard points. "Nasion", nose; "inion", the back of the head; left and right "Preauricular" means ear, dividing between "Nasion" and "inion" to be 10-20-20-20 and $10 \%$, electrodes placed. Other electrodes are placed with these electrodes to form a circle [8]. Figure 4 shows the location points of the 10-20 electrode system. 
Table 1. Signal acquisition methods used in brain computer interface technologies.

\begin{tabular}{|l|c|c|c|c|c|}
\hline Signal Acquisation Method & $\begin{array}{c}\text { Signal } \\
\text { Source Type }\end{array}$ & $\begin{array}{c}\text { Invasive/Non- } \\
\text { Invasive }\end{array}$ & $\begin{array}{c}\text { Spatial } \\
\text { Resolution }\end{array}$ & $\begin{array}{c}\text { Temporal } \\
\text { Resolution }\end{array}$ & Portability \\
\hline Electroencephalography (EEG) & Electrical & Non-invasive & $\sim 10 \mathrm{~mm}$ & $\sim 0.001 \mathrm{~s}$ & Portable \\
\hline Electrocorticography (ECoG) & Electrical & Semi-invasive & $\sim 1 \mathrm{~mm}$ & $\sim 0.003 \mathrm{~s}$ & Portable \\
\hline Magnetoencephalography (MEG) & Magnetic & Non-invasive & $\sim 5 \mathrm{~mm}$ & $\sim 0.05 \mathrm{~s}$ & Non-portable \\
\hline Positron emission tomography (PET) & Metabolic & Non-invasive & $\sim 1 \mathrm{~mm}$ & $\sim 0.2 \mathrm{~s}$ & Non-portable \\
\hline $\begin{array}{l}\text { single photon emission computed } \\
\text { tomography (SPECT or SPET) }\end{array}$ & Metabolic & Non-invasive & $\sim 1 \mathrm{~cm}$ & $\begin{array}{c}\sim 10 \mathrm{~s}-30 \\
\text { min }\end{array}$ & Non-portable \\
\hline $\begin{array}{l}\text { Functional magnetic resonance imaging } \\
\text { (fMRI), }\end{array}$ & Metabolic & Non-invasive & $\sim 1 \mathrm{~mm}$ & $\sim 1 \mathrm{~s}$ & Non-portable \\
\hline $\begin{array}{l}\text { Optical imaging (functional Near InfraRed } \\
\text { (fNIR)) }\end{array}$ & Metabolic & Non-invasive & $\sim 2 \mathrm{~cm}$ & $\sim 1 \mathrm{~s}$ & Portable \\
\hline Intracortical Neuron Recording & Electrical & invasive & $\sim 0.1 \mathrm{~mm}$ & $\sim 0.003 \mathrm{~s}$ & Portable \\
\hline
\end{tabular}

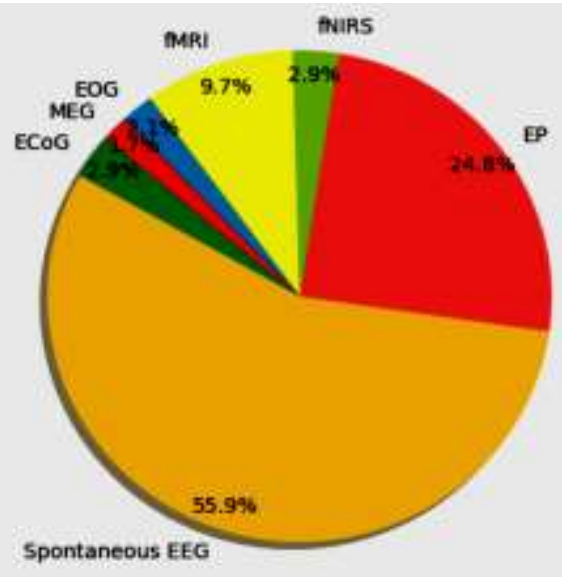

Figure 1. Usage rates of signal acquisition methods in the literature.

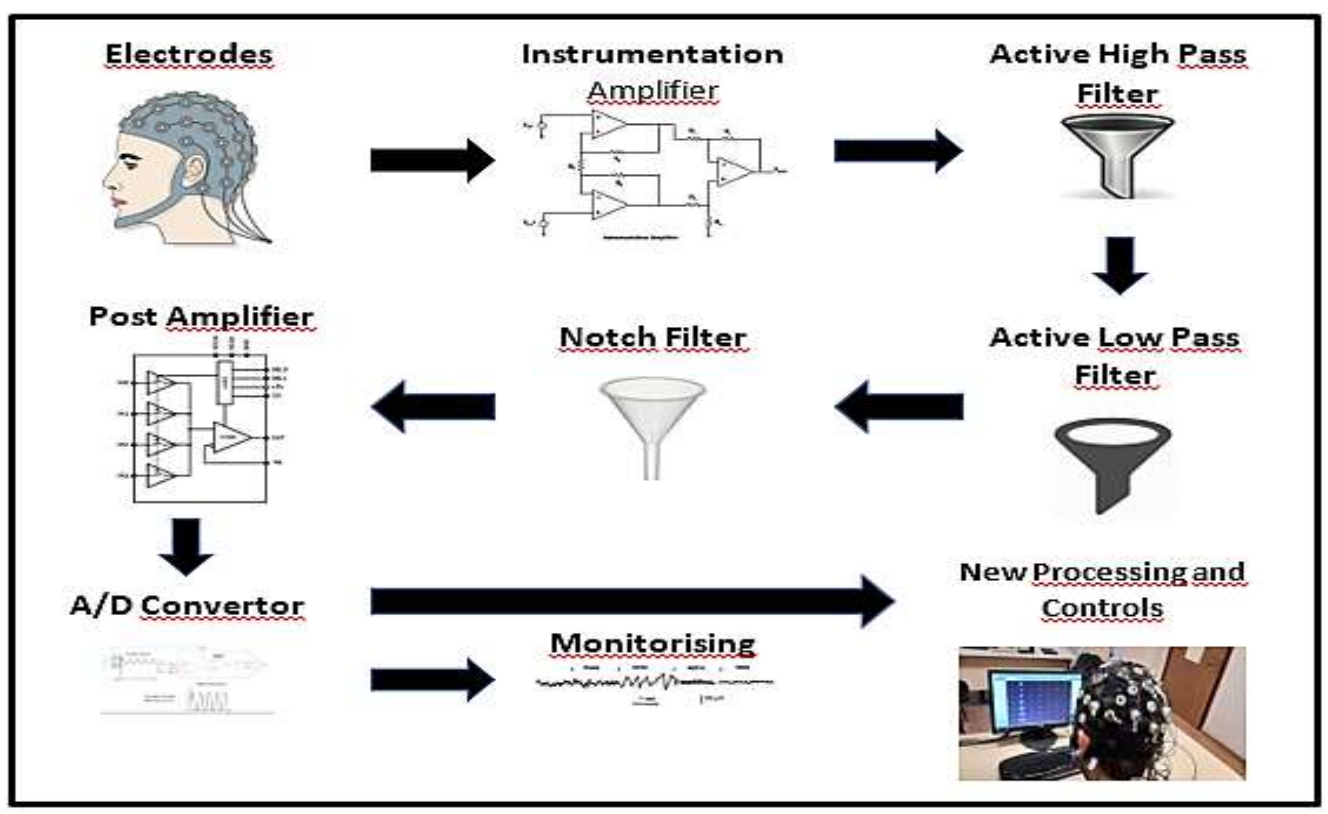

Figure 2. EEG block diagram. 


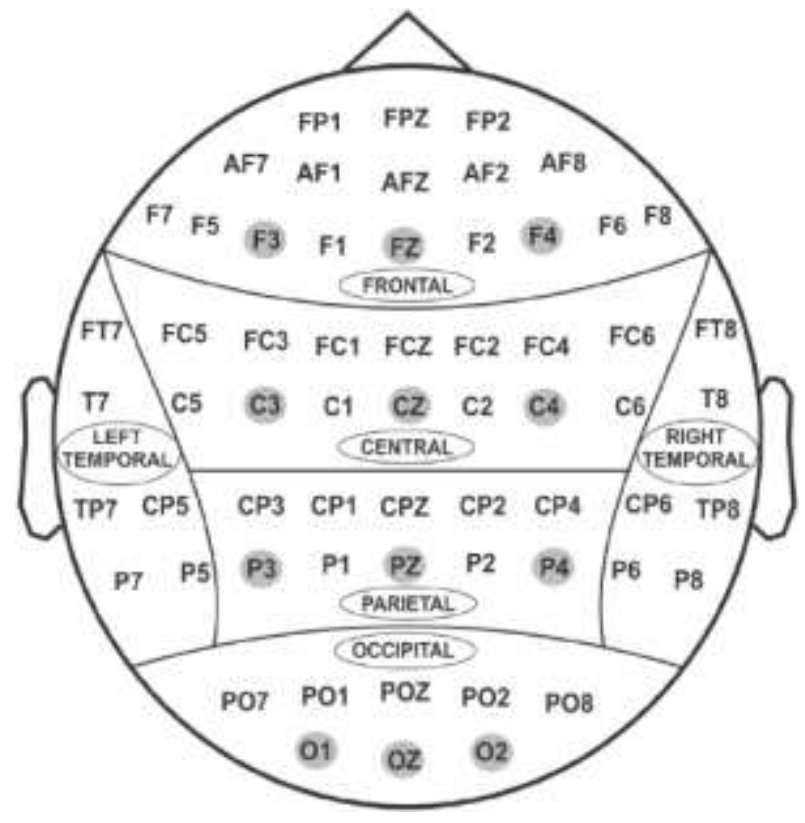

Figure 3. 10-20 elektrot sisteminin yerleşim noktaları [9].

In the use of EEG systems, a conductive gel or paste should be applied to bridge the gap between the scalp and the electrode and reduce the electrode impedance. However, with the development of dry electrodes, it eliminates the need for conductive gel or paste application, thereby reducing the electrode application time, allowing users to record EEGs for wired and wet electrode systems in impractical situations [10]. It has even been argued that EEG data recorded from a wireless dry electrode system can replace EEG data recorded with gel electrodes from a conventional system [11].

An EEG system should display a maximum of $6 \mu \mathrm{Vpp}$ input noise to detect $\mu \mathrm{V}$ level EEG signals. This nominal peak-to-peak noise can be converted to average square root (rms) noise, resulting in an integrated noise of $0.91 \mu \mathrm{Vrms}$. As a result, state-of-the-art bioamplifiers target $\mathrm{a}<1 \mu \mathrm{Vrms}$ noise for the input, usually 0.5-100 $\mathrm{Hz}$ bandwidth. Also, 1 / f noises are typically reduced by dynamic circuit techniques [12]. Signals are filtered and amplified between these limits.

\section{Signal processing}

Since the ionic current is formed inside the brain, it is measured in the scalp, and layers between the cortex and the electrodes, such as the skull, reduce the Signal-to-Noise Ratio (SNR) by approximately 5\%, which represents the relationship of the original brain signals to the measured EEG signals [13]. EEG recordings are often negatively affected by noise with different artifacts. Artifacts in the EEG recording are various species from different sources. Artifacts in EEG can originate from internal and external sources and mix noise into recordings in both temporal and spectral areas with broad frequency bands. Internal artifacts result from the patient's physiological activities (eg ECG, EMG / muscle artifacts, EOG) and movement. External artifacts are environmental interference, recording devices, electrode popup and cable motion.

In addition, some artifacts appear as regular periodic events, such as ECG or pulse (regular / periodic), while others may be extremely irregular. In order to increase the Signal-toNoise Ratio (SNR), operations that will clear the signal from artifacts should be done. Cleaning the artifact involves canceling or correcting the artifacts without disrupting the corresponding signal. This is done primarily in two ways: filtering and regression, or separation / separation of EEG data into other fields. With regression analysis, Independent Component Analysis (ICA), Principal Component Analysis (PCA) or Morphological Component Analysis (MCA), Blind Source Separation, Wavelet Transform, Empirical Mode Separation, Adaptive Filtering or their hybrid use are used to clear the signal from artifacts [14]. 


\section{Feature extraction}

Feature extraction in brain computer interfaces means identifying information in domains other than brain signals that are free from noise. These properties can be signal amplitude, signal mean, kurtosis, variance in the time domain as well as Fourier transform and mean frequency in the frequency domain. Also, a feature that can be valid for both domains is the information extracted from the wavelet transform [15].

The result appears to vary significantly from feature to feature. Feature selection provides less data and hence the classification system becomes less complex and increases the calculation of machine learning algorithms [16]. That is, it is important in terms of cost, working time and performance of the system whether or not to use which features for classification in feature selection [17].

Feature selection is used not only to achieve the smaller size of the feature matrix for classification, but also to select a corresponding subset of all available features that throw out irrelevant features from the matrix, which can reduce noise. Some of the feature selection methods used for this feature reduction are: Principal Component Analysis, Linear Discriminant Analysis, Factor Analysis, Multi Dimensional Scaling, Isometric Feature Mapping, Complex Band Power, Common Spatial Patterns [18].

\section{Classification}

A classification is made according to the control application using the feature matrix obtained from the appropriate feature selection methods. Classification techniques are used to identify different brain signals produced by the user. These identified signals are then converted into control commands for application interface purposes [19]. Classification methods can be divided into two as supervised and unsupervised. Supervised classification is a traditional classifier where weights of optimum values are applied to the predictive states as supervised labels.

It is clear that the classification techniques based on supervised learning are largely preferred in the literature compared to those based on unsupervised learning. Unattended techniques are mainly used for feature selection. However, unsupervised techniques such as Gaussian mix models have been used for EEG classification problems other than MI EEG processing, and may possibly be applied to MI EEG in future studies [20]. Various machine learning algorithms have been used as emotion classifiers such as support vector machine (SVM), K-nearest neighbors (K-NN), linear separation analysis (LDA), random forest, Naïve Bayes (NB) and Artificial Neural Network (NB). Therefore, in general, the choice of which classification algorithm can be used when designing a BCI largely depends on both the type of encoded brain signal and the type of application being controlled [21]. Figure 5 shows a diagram describing the estimates made by supervised classification method.

The unsupervised classification is the classifier where an estimate is added to the system to determine possible target characters and train the classifier. For example, Kindermans et al. They proposed a method that uses expectation maximization (EM) to train the system during an unattended free writing session. During use, the subject selects characters for a target word or phrase as in the traditional system. After each election, the classifier tries to retrain himself using an iterative process. First, EEG signals are classified according to a random initial system configuration. Then, looking at these classifications as real tags, system parameters are optimized as in a training session. Using 


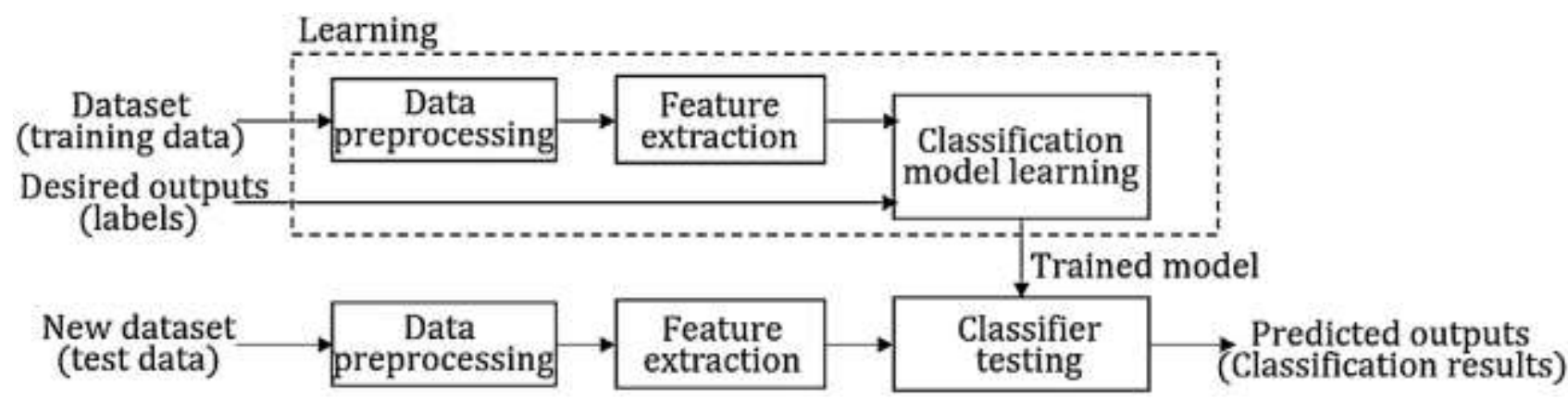

Figure 4. A diagram describing the estimates made by supervised classification method [22].

these parameters, EEG signals are reclassified and change alternately until the process gets close to a single configuration. This method depends on the initial configuration and may result in local optima that does not classify the signals correctly. In this study, the problem was solved by creating multiple initial configurations and running EM separately for each. The result with higher log probability will be selected as the true classifier [23],[24].

In recent years, classifiers have focused on identifying and designing classification methods that are compatible with the characteristics of EEG-based BCIs. In particular, topics such as low signal / noise ratio of EEG signals, which are the main challenges faced by classification methods for BCI, not being stationary over time, calibrating the classifiers with available training data of users' EEG signals, and eliminating overall low reliability and performance of existing BCIs. Adaptive classifiers have been developed in online applications to track changes in EEG features whose parameters are incrementally updated over time, i.e. to cope with EEG stability. Adaptive classifiers are also used to deal with limited training data by learning online, so less offline training data is required. Transfer learning techniques aim to transfer properties or classifiers from a single area. For this reason, they aim to address the nonstationary and limited educational data within the subjects by completing a small number of educational data that can be obtained with the data transferred from other fields. Finally, to compensate for the low EEG signal-to-noise ratio and poor reliability of existing BCIs, new methods for processing and classifying signals in one step were combined, combining feature extraction, feature selection, and classification. This was accomplished using matrix (especially Riemann methods) and tensor classifiers, as well as deep learning. The additional methods explored specifically aimed at learning with limited amounts of data and dealing with multiple class problems [25].

The types of EEG signal classified used in BCI

The purpose of this study is to investigate which classification method is widely preferred in EEG signal types used practically in brain computer interfaces. For this purpose, this section describes what type of EEG signals are used in BCI in practice.

In brain computer interface systems, control application is done by solving the meaning of thought. For this, it is necessary to detect and classify a brain signal pattern or the response expected from the brain for a specific task. EEG based BBA systems that can be used in practice are named according to the type of EEG signal used. The brain signals related to the event used in the brain computer interfaces in practice are: P300 signals resulting from the acquisition of potentials, steady state visual evoked potentials 
and slow cortical potentials. The mental strategy that needs to be developed for these potentials to arise is to be focused on a certain stimulus. Cortical oscillations, on the other hand, are sensorimotor rhythms obtained from the sensory motor cortex of the brain, for example, with the imagination of a limb movement. For this reason, his mental strategy has been named as an engine dream [26]. $\mathrm{BCI}$ is based on control signals received directly from the brain. Some of these signals are relatively easy to remove and some are difficult and require some extra pretreatment.
These control signals can be divided into three categories: Excited signals, Spontaneous signals and Hybrid signals [2]. It is showed in Table 2. We concentrated on the 4 most commonly used EEG signal types in practice among the 3 categories mentioned in this study: A Sensori Motor Rhythms ( $\mu$ and $\beta$ rhythms) based BBA systems. K Slow Cortical Potential (YKP) based BBA systems. 300 P300 Signal based BBA systems. Steady State Visual Evoked Potential based BBA systems. Table 3 contains summary information compiled from studies related to this subject.

Table 2. Mental control signals [2].

\begin{tabular}{|c|c|c|c|c|c|}
\hline \multicolumn{6}{|c|}{ MENTAL CONTROL SIGNALS } \\
\hline \multicolumn{2}{|c|}{ EVOKED } & \multicolumn{3}{|c|}{ SPONTANEUS } & HYBRID \\
\hline $\begin{array}{l}\text { SSEP } \\
\text { signals are brain } \\
\text { signals that are } \\
\text { generated when the } \\
\text { subject } \\
\text { perceives periodic } \\
\text { stimulus such as } \\
\text { flickering image, } \\
\text { modulated sound, } \\
\text { and even when the } \\
\text { subject feel some } \\
\text { vibrations }\end{array}$ & $\begin{array}{l}\text { P300 } \\
\text { It is an EEG } \\
\text { signal that } \\
\text { appears after } \\
\text { almost } 300 \mathrm{~ms} \\
\text { when the } \\
\text { subject is } \\
\text { exposed to } \\
\text { infrequent or } \\
\text { surprising task. }\end{array}$ & $\begin{array}{l}\text { Motor and } \\
\text { Sensorymotor } \\
\text { Rhythms } \\
\text { are those } \\
\text { rhythms related } \\
\text { to } \\
\text { motor actions } \\
\text { such as moving } \\
\text { arms. These } \\
\text { rhythms are } \\
\text { coming from } \\
\text { over the motor } \\
\text { cortex with } \\
\text { frequency bands } \\
\text { located at } \mu \\
(\simeq 8-13 \text { Hz) } \\
\text { and } \beta \text { ( } \simeq 13-30 \\
\text { Hz). The } \\
\text { amplitude of } \\
\text { these rhythms } \\
\text { could be } \\
\text { controlled by } \\
\text { the subject. }\end{array}$ & $\begin{array}{l}\text { SCP } \\
\text { (Slow Cortical } \\
\text { Potentials) } \\
\text { is an EEG } \\
\text { signal that } \\
\text { belongs to a } \\
\text { frequency } \\
\text { below } 1 \mathrm{~Hz} \text {. It } \\
\text { is a low } \\
\text { frequency } \\
\text { potential } \\
\text { detected in the } \\
\text { frontal and } \\
\text { central parts of } \\
\text { the cortex; it is } \\
\text { also the results } \\
\text { of the } \\
\text { depolarization } \\
\text { level shifts in } \\
\text { the upper } \\
\text { cortical } \\
\text { dendrites. }\end{array}$ & $\begin{array}{l}\text { Non Motor } \\
\text { Cognitive Tasks } \\
\text { Non-motor } \\
\text { cognitive tasks } \\
\text { mean that } \\
\text { cognitive tasks } \\
\text { are used to } \\
\text { drive the BCI. } \\
\text { Many of the } \\
\text { tasks could be } \\
\text { performed such } \\
\text { as music } \\
\text { imagination, } \\
\text { visual counting, } \\
\text { mental rotation, } \\
\text { and } \\
\text { mathematical } \\
\text { computation }\end{array}$ & $\begin{array}{l}\text { Hybrid } \\
\text { signals mean } \\
\text { that a } \\
\text { combination } \\
\text { of brain } \\
\text { generated } \\
\text { signals } \\
\text { are used for } \\
\text { control. } \\
\text { Therefore, } \\
\text { instead of } \\
\text { only one type } \\
\text { of signals is } \\
\text { measured and } \\
\text { used in the } \\
\text { BCI system, } \\
\text { a hybrid of } \\
\text { signals are } \\
\text { utilized. } \\
\text { The main } \\
\text { purpose } \\
\text { behind using } \\
\text { two or more } \\
\text { types of brain } \\
\text { signals as } \\
\text { input to a } \\
\text { BCI system } \\
\text { is the } \\
\text { reliability and } \\
\text { to avoid the } \\
\text { disadvantages } \\
\text { of } \\
\text { each type of } \\
\text { signals. }\end{array}$ \\
\hline
\end{tabular}


Table 3. Information from some studies on brain computer interface in recent years

\begin{tabular}{|c|c|c|c|c|c|c|c|}
\hline Source & \begin{tabular}{|l|} 
EEG \\
Signal \\
Types \\
\end{tabular} & \begin{tabular}{|l|} 
Classification \\
Methods
\end{tabular} & Application & Accuracy & Subject Type & Preprocessing & \begin{tabular}{|l|} 
Feature \\
Extraction \\
Method \\
\end{tabular} \\
\hline$[27]$ & P300 & PCA & $\begin{array}{l}\text { P300-based text editor } \\
\text { for Android-based } \\
\text { devices }\end{array}$ & 97.19 & Healthy & $\begin{array}{l}\text { Common average } \\
\text { reference spatial } \\
\text { filte }\end{array}$ & PCA \\
\hline$[28]$ & P300 & \begin{tabular}{|l|} 
LDA \\
eSVM \\
CNN-1 \\
MCNN1 \\
EFLD \\
SRDA \\
STDA \\
HODA+LDA \\
SWLDA
\end{tabular} & \begin{tabular}{|l|} 
Defining tensor-based \\
feature reduction \\
technique \\
Higher Order Spectral \\
Regression Discriminant \\
Analysis (HOSRDA)
\end{tabular} & $\begin{array}{l}\text { LDA } 96.5 \\
\text { eSVM } 96.5 \\
\text { CNN-1 } 94.5 \\
\text { MCNN1 } 95.5 \\
\text { EFLD } 95 \\
\text { SRDA } 95 \\
\text { STDA } 95 \\
\text { HODA+LDA } 94 \\
\text { SWLDA } 92.5 \\
\text { Reg. + } \\
\text { HODA+LDA } 92\end{array}$ & $\begin{array}{l}\text { Healthy } \\
\text { (Data of BCI } \\
\text { competition } \\
\text { III) }\end{array}$ & $\begin{array}{l}\text { Bandpass filtered } \\
\text { in the band } 0.1-60 \\
\mathrm{~Hz} \\
\text { Each trial was } \\
\text { bandpass filtered } \\
\text { between } 0.1 \text { and } \\
10 \mathrm{~Hz} \text { with } 8- \\
\text { order Chebyshev } \\
\text { type I filter and } \\
\text { then decimated to } \\
20 \mathrm{~Hz}\end{array}$ & HOSRDA \\
\hline$[29]$ & P300 & LDA & $\begin{array}{l}\text { Impact of fatigue } \\
\text { brain behavior on } \\
\text { P300 signals and } \\
\text { developing wavelet } \\
\text { multiple solution } \\
\text { complex network to } \\
\text { analyze P300 EEG } \\
\text { signals }\end{array}$ & 95.42 & Healthy 10 & $\begin{array}{l}\text { The signals are } \\
\text { filtered with a } \\
\text { bandpass of 1- } \\
40 \mathrm{~Hz} \text {. } \\
\text { The } \\
\text { Independent } \\
\text { Component } \\
\text { Analysis (ICA) } \\
\text { method is } \\
\text { applied to } \\
\text { remove eye } \\
\text { movement and } \\
\text { blink artifacts. }\end{array}$ & - \\
\hline$[30]$ & P300 & $\begin{array}{l}\text { Naïve- } \\
\text { Bayes }\end{array}$ & $\begin{array}{l}\text { Designing an } \\
\text { interface for social } \\
\text { attention disorders } \\
\text { such as autism } \\
\text { spectrum disorder } \\
\text { using Virtual Reality }\end{array}$ & Between 85-90 & $\begin{array}{l}13 \text { Healthy } \\
4 \text { autism } \\
\text { spectrum } \\
\text { disorder }\end{array}$ & $\begin{array}{l}\text { Notch: } 50 \mathrm{~Hz} \\
2 \mathrm{~Hz}-30 \mathrm{~Hz}, 8 \mathrm{th} \\
\text { order } \\
\text { Butterworth } \\
\text { band-pass filter }\end{array}$ & $\begin{array}{l}\text { FC filter } \\
\text { model } \\
\text { Max-SNR } \\
\text { filter } \\
\text { model } \\
\text { spatial } \\
\text { filtering } \\
\end{array}$ \\
\hline$[22]$ & P300 & SVM & $\begin{array}{l}\text { In P300 spells, based } \\
\text { on the distance of } \\
\text { each row and column } \\
\text { according to the } \\
\text { targeted character, } \\
\text { separating the training } \\
\text { data into groups at the } \\
\text { same distance, } \\
\text { measuring the } \\
\text { accuracy rate in the } \\
\text { eSVM classifier, } \\
\text { examining its effect } \\
\text { on the classifier } \\
\text { diversity. }\end{array}$ & 97 & $\begin{array}{l}\text { Healthy } \\
\text { (Data of } \\
\text { BCI } \\
\text { competition } \\
\text { III) }\end{array}$ & $\begin{array}{l}\text { Bandpass } \\
\text { frequency } \\
\text { filtering } \\
\text { between } 0.1 \text { and } \\
10 \mathrm{~Hz}\end{array}$ & eSVM \\
\hline
\end{tabular}




\begin{tabular}{|c|c|c|c|c|c|c|c|}
\hline$[31]$ & P300 & SVM & $\begin{array}{l}\text { An approach based on } \\
\text { multipurpose dual } \\
\text { differential evolution } \\
\text { (MOBDE) algorithm to } \\
\text { optimize system } \\
\text { accuracy and number of } \\
\text { EEG channels used for } \\
\text { classification }\end{array}$ & 92.8 (averaged) & Healthy & $\begin{array}{l}\text { A band-pass filter } \\
\text { of cut-off } \\
\text { frequencies } \\
\text { between } 1 \text { and } 10 \\
\mathrm{~Hz}\end{array}$ & $\begin{array}{l}\text { down } \\
\text { sampling }\end{array}$ \\
\hline$[32]$ & P300 & $\begin{array}{l}\text { SWLDA, } \\
\text { FLDA }\end{array}$ & $\begin{array}{l}\text { To apply the vibration } \\
\text { movement with piezo } \\
\text { activators to the fingers } \\
\text { in the Oddball paradigm } \\
\text { method, to ensure the } \\
\text { formation of P300 and } \\
\text { to use for the } \\
\text { classification of } 2 \text { and } 4\end{array}$ & $\begin{array}{l}2 \text { class. } 85 \\
4 \text { class. } 60\end{array}$ & Healthy & $\begin{array}{l}\text { band-pass filtered } \\
\text { from } 0.53 \text { to } 120 \\
\mathrm{~Hz}\end{array}$ & $\begin{array}{l}\text { moving } \\
\text { average and } \\
\text { down } \\
\text { sampling }\end{array}$ \\
\hline$[33]$ & P300 & SVM & $\begin{array}{l}\text { Classification of } \\
\text { schizophrenia patients } \\
\text { and healthy individuals } \\
\text { using both sensor level } \\
\text { and source level features } \\
\text { extracted from EEG } \\
\text { signals recorded during } \\
\text { an auditory oddball task }\end{array}$ & 88.24 & $\begin{array}{l}34 \\
\text { Schizophrenia } \\
34 \text { Healthy }\end{array}$ & $\begin{array}{l}\text { band-pass filtered } \\
\text { at } 1 \text { to } 30 \mathrm{~Hz}\end{array}$ & \begin{tabular}{|l|} 
sensor-level \\
features \\
Source level \\
features \\
the \\
combined \\
features
\end{tabular} \\
\hline$[34]$ & P300 & SVM & $\begin{array}{l}\text { Three distinctive } \\
\text { feature-based multi-core } \\
\text { learning (MKL) is } \\
\text { recommended to learn } \\
\text { an efficient P300 } \\
\text { classifier to improve } \\
\text { character recognition } \\
\text { accuracy in a P300 } \\
\text { speller BCI. } \\
\end{array}$ & 98 & Healthy & $\begin{array}{l}\text { 4th-order } \\
\text { bandpass } \\
\text { Chebyshev Type I } \\
\text { between } 0.1 \mathrm{~Hz} \\
\text { and } 20 \mathrm{~Hz} .\end{array}$ & \begin{tabular}{|l} 
the three \\
discriminant \\
features: \\
Raw \\
samples \\
Amplitude \\
Negative \\
area
\end{tabular} \\
\hline$[35]$ & P300 & $\begin{array}{l}\text { BN (Type of } \\
\text { CNN) }\end{array}$ & $\begin{array}{l}\text { Develop a new CNN } \\
\text { called BN (Batch } \\
\text { Normalization) to detect } \\
\text { P300 signals }\end{array}$ & 84 & Healthy & $\begin{array}{l}8 \text { th-order } \\
\text { bandpass } \\
\text { Butterworth filter } \\
0.1 \text { and } 20 \mathrm{~Hz} . \\
\end{array}$ & $\mathrm{CNN}$ \\
\hline$[36]$ & P300 & SVM & $\begin{array}{l}\text { To design a new lie } \\
\text { detection system and } \\
\text { apply } 2 \text { new feature } \\
\text { extraction methods in } \\
\text { the system }\end{array}$ & 88.7 & Healthy & $\begin{array}{l}\text { band pass at } 0.01 \\
\mathrm{~Hz} \text { to } 100 \mathrm{~Hz} \\
\text { ocular artifact } \\
\text { reduction }\end{array}$ & \begin{tabular}{|l|} 
Wavelet \\
packet \\
transform \\
Nonlinear \\
interdepende \\
nces
\end{tabular} \\
\hline$[37]$ & P300 & Unsupervised & $\begin{array}{l}\text { Collection of } \\
\text { matching filter and } \\
\text { context analysis for } \\
\text { P300 detection, use of } \\
\text { unsupervised learning } \\
\text { systems }\end{array}$ & 91.66 & $\begin{array}{l}\text { Healthy } \\
\text { (physionet. } \\
\text { org) }\end{array}$ & $\begin{array}{l}\text { Band-Pass } \\
\text { Filtering } 0.15 \\
\mathrm{~Hz} \text { and } 5 \mathrm{~Hz} \\
\text { cancel the } \\
\text { saccadic spike } \\
\text { poten- tial (SP) } \\
\text { ICA } \\
\text { Wiener filtering } \\
\end{array}$ & - \\
\hline$[38]$ & P300 & LDA & $\begin{array}{l}\text { To evaluate the } \\
\text { somatosensory } \\
\text { discrimination and } \\
\text { command after using } \\
\text { the vibrotactile P300- } \\
\text { based Brain- } \\
\text { Computer Interface } \\
\text { (BCI) in } \\
\text { Unresponsive } \\
\text { Vigilance Syndrome } \\
\text { (UWS) and to } \\
\text { investigate the } \\
\text { predictive role of this } \\
\text { cognitive process on } \\
\text { clinical outcomes. }\end{array}$ & 97 & $\begin{array}{l}\text { Thirteen } \\
\text { UWS } \\
\text { patients and } \\
\text { six healthy }\end{array}$ & $\begin{array}{l}\text { The data were } \\
\text { notch-filtered at } \\
50 \mathrm{~Hz} \text { and } \\
\text { bandpass- } \\
\text { filtered within } \\
0.1-30 \mathrm{~Hz} \text {. } \\
\text { Trials with an } \\
\text { amplitude above } \\
100 \mathrm{mV} \text { were } \\
\text { automati- cally } \\
\text { rejected. }\end{array}$ & - \\
\hline
\end{tabular}




\begin{tabular}{|c|c|c|c|c|c|c|c|}
\hline$[39]$ & P300 & LDA & $\begin{array}{l}\text { The auditory paradigm, } \\
\text { also known as the drip- } \\
\text { stimulating hearing BCI } \\
\text { paradigm, the audio } \\
\text { paradigm (BP), called } \\
\text { drip paradigm (BP), was } \\
\text { compared with the } \\
\text { difficulty and difficulty } \\
\text { scores to demonstrate the } \\
\text { advantages of online } \\
\text { accuracy and DP. }\end{array}$ & 80.87 (averaged) & Healthy & $\begin{array}{l}\text { filtered with a } \\
\text { third-order Butter- } \\
\text { worth band-pass } \\
\text { filter between } 0.1 \\
\text { and } 30 \mathrm{~Hz} \text {. }\end{array}$ & \\
\hline$[40]$ & P300 & LDA & $\begin{array}{l}\text { The effect of the } \\
\text { translucent face model } \\
\text { (STF-P) (the subject } \\
\text { could see the target } \\
\text { character when flashing) } \\
\text { and the traditional face } \\
\text { model (FP) (the subject } \\
\text { could not see the target } \\
\text { character when flashing) } \\
\text { Performance comparison } \\
\text { in terms of transparency } \\
\text { in terms of transparency }\end{array}$ & 95.2 & Healthy & $\begin{array}{l}\text { Band-pass filtered } \\
0.5-30 \mathrm{~Hz}\end{array}$ & $\begin{array}{l}\text { Downsampli } \\
\text { ng } \\
\text { Winsorizing }\end{array}$ \\
\hline$[41]$ & MI & SVM & $\begin{array}{l}\text { Examination of EEG } \\
\text { signals of } 4 \text { different } \\
\text { states } \\
\text { Turning hands on or off } \\
\text { with the audio video } \\
\text { command } \\
\text { Open and close hands } \\
\text { with silent video } \\
\text { Pressing the piano with } \\
\text { the same two ways } \\
\text { command }\end{array}$ & 87.5 & Healthy & $\begin{array}{l}\text { band-pass filtered } \\
\text { from } 0.5 \text { to } 40 \mathrm{~Hz} \\
\text { common average } \\
\text { reference } \\
\text { visual in- spection }\end{array}$ & $\begin{array}{l}\text { Common } \\
\text { Spatial } \\
\text { Pattern } \\
\text { (CSP) filter }\end{array}$ \\
\hline$[42]$ & MI & Naive Bayes & $\begin{array}{l}\text { A correlation analysis } \\
\text { was performed between } \\
\text { various quantitative } \\
\text { evaluation metrics of } \\
\text { motor imageries. For this, } \\
\text { the actions to be done by } \\
\text { the subjects were taught } \\
\text { in the first step, the most } \\
\text { effective image strategy } \\
\text { was determined in the } 2 \\
\text { and } 3 \text { steps. }\end{array}$ & 87 (ortalama) & Healthy & $\begin{array}{l}\text { bandpass filtered in } \\
4- \\
40 \mathrm{~Hz} \text { range with a } \\
4 \text { th-order } \\
\text { Butterworth filter, }\end{array}$ & $\begin{array}{l}\text { Common } \\
\text { Spatial } \\
\text { Pattern } \\
\text { (CSP) filter }\end{array}$ \\
\hline$[43]$ & MI & $\begin{array}{l}\text { Linear } \\
\text { Regression }\end{array}$ & $\begin{array}{l}\text { Design a system to } \\
\text { modulate activity in the } \\
\text { default mode network } \\
\text { (DMN) without involving } \\
\text { sensorimotor paths by } \\
\text { instructing to activate } \\
\text { their reference memories } \\
\text { or focus on a process } \\
\text { without reminder content. }\end{array}$ & \begin{tabular}{|l|} 
ALS 60.8 \\
Healthy 62.5
\end{tabular} & $\begin{array}{l}11 \text { Healthy and } \\
5 \text { ALS }\end{array}$ & ICA & $\begin{array}{l}\text { computed the } \\
\text { trial-wise } \\
\text { log- } \\
\text { bandpower } \\
\text { of the } \\
\text { averaged, } \\
\text { combined y- } \\
\text { and a-range } \\
\text { at every } \\
\text { channel } \\
\text { location } \\
\text { using the } \\
\text { Fourier } \\
\text { transform. }\end{array}$ \\
\hline [44] & MI & LDA & $\begin{array}{l}30 \text { healthy SMR-BCI } \\
\text { participants were } \\
\text { trained to control right } \\
\text { hand movement and } \\
\text { SMR-based BCI on } \\
\text { separate days for five } \\
\text { days with traditional } \\
\text { bar feedback (CB) or } \\
\text { visual funnel feedback } \\
\text { (UF) or multimodal } \\
\text { (visual and auditory) } \\
\text { funnel feedback (MF). }\end{array}$ & 63 & 30 healthy & & $\begin{array}{l}\text { power } \\
\text { spectral } \\
\text { density } \\
\text { (PSD) }\end{array}$ \\
\hline
\end{tabular}




\begin{tabular}{|c|c|c|c|c|c|c|c|}
\hline [45] & $\begin{array}{l}\text { Hybrid } \\
\text { P300- } \\
\text { SSVEP }\end{array}$ & \begin{tabular}{|l} 
SSVEP-> \\
canonical \\
correlation \\
analysis \\
(CCA) \\
P300 -> \\
SWLDA
\end{tabular} & $\begin{array}{l}\text { The hybrid spelling } \\
\text { consists of nine panels } \\
\text { that vibrate at different } \\
\text { frequencies. Each panel } \\
\text { contains four different } \\
\text { characters that appear in } \\
\text { a random order. The } \\
\text { vibrating panel and the } \\
\text { periodically updated } \\
\text { character evoke the } \\
\text { dual-frequency SSVEP, } \\
\text { while the strange } \\
\text { stimulus of the target } \\
\text { character evokes the } \\
\text { P300. }\end{array}$ & $\begin{array}{l}\text { SSVEP } 89 \\
\text { P300 90 } \\
\text { Hybrid } 93\end{array}$ & Healthy 10 & $\begin{array}{l}\text { band-pass-filtered } \\
\text { at }[250] \mathrm{Hz}\end{array}$ & \\
\hline [46] & mVEP & SVM & $\begin{array}{l}\text { A red line sliding to the } \\
\text { left in random order } \\
\text { appears in each of the } 6 \\
\text { stimuli placed in a } \\
\text { rectangular visual } \\
\text { interface. Contribution } \\
\text { of using deep learning } \\
\text { to the classification in } \\
\text { the selection of } \\
\text { objective features }\end{array}$ & $\begin{array}{l}\text { Compressed } \\
\text { sensing and deep } \\
\text { learning features } \\
87.5 \\
\text { Conventional } \\
\text { mVEP features } \\
84.0\end{array}$ & Healthy 11 & $\begin{array}{l}50 \mathrm{~Hz} \text { notch filter } \\
\text { bandpass filtered } \\
\text { within } 0.5-10 \mathrm{~Hz}\end{array}$ & \begin{tabular}{|l|} 
Deep \\
learning
\end{tabular} \\
\hline [47] & SCP & MLP & $\begin{array}{l}\text { Each signal is first } \\
\text { divided into wavelet } \\
\text { sub-marks, and then } \\
\text { features such as } \\
\text { Logenergy entropy are } \\
\text { extracted from these } \\
\text { sub-marks. These } \\
\text { features are fed to an } \\
\text { MLP for classification. } \\
\text { Finally, it was compared } \\
\text { with SVM and KNN. }\end{array}$ & $\begin{array}{l}\text { MLP 92.83 } \\
\text { KNN } 89.76 \\
\text { SVM } 86.01\end{array}$ & \begin{tabular}{|l} 
BCI Comp. \\
2003 datasets
\end{tabular} & & $\begin{array}{l}\text { Wavelet } \\
\text { packet } \\
\text { decompositi } \\
\text { on (WPD) } \\
\text { Log energy } \\
\text { entropy }\end{array}$ \\
\hline
\end{tabular}

Funding: The author(s) received no financial support for the research, authorship, and/or publication of this article.

Conflict of Interest: The authors declare that they have no conflict of interest.

Ethical statement: This article does not contain any studies with human participants or animals performed by any of the authors.

\section{Open Access Statement}

This is an open access journal which means that all content is freely available without charge to the user or his/her institution under the terms of the Creative Commons Attribution NonCommercial License (http://creativecommons.org/licenses/bync/4.0). Users are allowed to read, download, copy, distribute, print, search, or link to the full texts of the articles, without asking prior permission from the publisher or the author.

\section{References}

[1]Daly JJ, Huggins JE. Brain-computer interface: current and emerging rehabilitation applications. Arch Phys Med Rehabil. 2015 Mar;96(3 Suppl):S1-7.

[2]Rabie A. Ramadan, Athanasios V. Vasilakos. Brain computer interface: control signals review. Neurocomputing. 2017;223:26-44

[3]Sarah N. Abdulkader, Ayman Atia, MostafaSami M. Mostafa. Brain computer interfacing: Applications and challenges. Egyptian Informatics Journal. 2015;16(2): 213-230.

[4]Nicolas-Alonso LF, Gomez-Gil J. Brain computer interfaces, a review. Sensors (Basel). 2012;12(2):1211-79. 
[5]Cohen MX. Where EEG Come From Does and What Does It Mean? Trends Neurosci. 2017 Apr;40(4):208-218.

[6]Lee S, Cho H, Kim K, Jun SC. Simultaneous EEG Acquisition System for Multiple Users: Development and Related Issues. Sensors (Basel). 2019;19(20):4592.

[7]Bhagawati AJ and Chutia R. Design of Single Channel Portable EEG Signal Acquisition System for Brain Computer Interface Application. Int J Biomed Eng Sci. 2016;3(1):37-44.

[8]Jasper HH. The 10/20 international electrode system. Electroencephalography and Clinical Neurophysiology. 1958;10(2) 37075.

[9]Kamarajan C, Pandey AK, Chorlian DB, et al. Deficient Event-Related Theta Oscillations in Individuals at Risk for Alcoholism: A Study of Reward Processing and Impulsivity Features. PLoS One. 2015 Nov 18;10(11):e0142659.

[10] Kam JWY, Griffin S, Shen A, et al. Systematic comparison between a wireless EEG system with dry electrodes and a wired EEG system with wet electrodes. Neuroimage. 2019;184:119-29.

[11] Wyckoff SN, Sherlin LH, Ford NL, Dalke D. Validation of a wireless dry electrode system for electroencephalography. J Neuroeng Rehabil. 2015;12:95.

[12] Xu J, Mitra S, Van Hoof C, et al. Active Electrodes for Wearable EEG Acquisition: Review and Electronics Design Methodology. IEEE Rev Biomed Eng. 2017;10:187-98.

[13]Ball T, Kern M, Mutschler I, Aertsen A, Schulze-Bonhage A. Signal quality of simultaneously recorded invasive and noninvasive EEG. Neuroimage. 2009;46(3):708-16.
[14] Islam MK, Rastegarnia A, and Yang Z. Les méthodes de détection et de rejet d'artefact de l'EEG de scalp: revue de littérature. Neurophysiol Clin. 2016;46(4-5): 287-305.

[15] Abootalebi V, Moradi MH, and Khalilzadeh MA. A new approach for EEG feature extraction in P300-based lie detection. Comput Methods Programs Biomed. 2009;94(19): 48-57.

[16] Nandy A, Alahe MA, Nasim Uddin SM, et al. Feature extraction and classification of EEG signals for seizure detection. 1st Int. Conf. Robot. Electr. Signal Process. Tech. ICREST. 2019; 480-85.

[17] Ebrahimzadeh E, Pooyan M, and Bijar A. A novel approach to predict sudden cardiac death (SCD) using nonlinear and timefrequency analyses from HRV signals. PLoS One. vol. 2014;9(2): 1-14.

[18]Nakra A and Duhan M. Feature Extraction and Dimensionality Reduction Techniques with Their Advantages and Disadvantages for EEG-Based BCI System : A Review. The IUP Journal of Computer Sciences. 2020;14(1): 21-34.

[19]Hong KS, Khan MJ, Hong MJ. Feature Extraction and Classification Methods for Hybrid fNIRS-EEG Brain-Computer Interfaces. Front Hum Neurosci. 2018;12:246.

[20]Padfield N, Zabalza J, Zhao H, et al. EEGBased Brain-Computer Interfaces Using Motor-Imagery: Techniques and Challenges. Sensors (Basel). 2019;19(6):1423.

[21] Al-Nafjan A, Hosny M, Al-Ohali Y, et al. Review and Classification of Emotion Recognition Based on EEG Brain-Computer Interface System Research: A Systematic Review. Applied Sciences. 2017; 7(12):1239. 
[22] Yu-Ri Lee, Hyoung-Nam Kim. A data partitioning method for increasing ensemble diversity of an eSVM-based P300 speller. Biomed Signal Process and Control. 2018;39:53-63.

[23] Speier W, Arnold C, Pouratian N. Integrating language models into classifiers for BCI communication: a review. J Neural Eng. 2016;13(3):031002.

[24] Kindermans PJ, Verstraeten D, Schrauwen B. A bayesian model for exploiting application constraints to enable unsupervised training of a P300-based BCI. PLoS One. 2012;7(4):e33758.

[25]Lotte F, Bougrain L, Cichocki A, Clerc M, Congedo M, Rakotomamonjy A, Yger F. A review of classification algorithms for EEGbased brain-computer interfaces: a 10 year update. J Neural Eng. 2018;15(3):031005.

[26] Oralhan Z. Durağan hal görsel uyaran tabanli beyin bilgisayar arayüzü için optimum uyaran özelliklerinin belirlenmesi ve gerçeklenmesi. Doktora Tezi. Erciyes University. 2016.

[27]Elsawy AS, Eldawlatly S, Taher M, Aly GM. MindEdit: A P300-based text editor for mobile devices. Comput Biol Med. 2017;80:97-106.

[28] Jamshidi Idaji M, Shamsollahi MB, and Hajipour Sardouie S. Higher order spectral regression discriminant analysis (HOSRDA): A tensor feature reduction method for ERP detection. Pattern Recognit. 2017;70:152-62.

[29] Gao ZK, Wang ZB, Yang YX, et al. Wavelet multiresolution complex network for decoding brain fatigued behavior from P300 signals. Phys A Stat Mech its Appl. 2018; 506(8):221-28.

[30] Amaral CP, Simões MA, Mouga S, et al. A novel Brain Computer Interface for classification of social joint attention in autism and comparison of 3 experimental setups: A feasibility study. J Neurosci Methods. 2017;290:105-15.

[31]Chaurasiya RK, Londhe ND, and Ghosh S. Multi-objective binary DE algorithm for optimizing the performance of Devanagari script-based P300 speller. Biocybern Biomed Eng. 2017;37(3): 422-31.

[32] Hori J and Okada N. Classification of tactile event-related potential elicited by Braille display for brain-computer interface. Biocybern Biomed Eng. 2017;37(1):13542.

[33] Shim M, Hwang HJ, Kim DW, et al. Machine-learning-based diagnosis of schizophrenia using combined sensor-level and source-level EEG features. Schizophr Res. 2016;176(2-3):314-19.

[34]Kyungae Yoon, Kiseon Kim. Multiple kernel learning based on three discriminant features for a P300 speller BCI. Neurocomputing. 2017;237:133-144.

[35]Liu M, Wu W, Gu Z, et al. Deep learning based on Batch Normalization for P300 signal detection. Neurocomputing. 2018; 275:288-97.

[36] Wang H, Chang W, and Zhang C. Functional brain network and multichannel analysis for the P300-based brain computer interface system of lying detection. Expert Syst Appl. 2016;53:117-28.

[37]Lafuente V, Gorriz JM, Ramirez J, et al. P300 brainwave extraction from EEG signals: An unsupervised approach. Expert Syst Appl. 2017; 74: 1-10.

[38] Spataro R, Heilinger A, Allison B, et al. Preserved somatosensory discrimination predicts consciousness recovery in unresponsive wakefulness syndrome. Clin Neurophysiol. 2018;129(6):1130-136.

[39]Huang M, Jin J, Zhang Y, et al. Usage of drip drops as stimuli in an auditory P300 BCI 
paradigm. Cogn Neurodyn. 2018;12(1): 8594.

[40]Cheng J, Jin J, Wang X. Comparison of the BCI Performance between the Semitransparent Face Pattern and the Traditional Face Pattern. Comput Intell Neurosci. 2017;2017:1323985.

[41]Bian Y, Qi H, Zhao L, et al. Improvements in event-related desynchronization and classification performance of motor imagery using instructive dynamic guidance and complex tasks. Comput Biol Med. 2018;96:266-273.

[42] Vasilyev A, Liburkina S, Yakovlev L, et al. Assessing motor imagery in brain-computer interface training: Psychological and neurophysiological correlates. Neuropsychologia. 2017;97:56-65.

[43] Hohmann MR, Fomina T, Jayaram V, Widmann N, Förster C, Just J, Synofzik M, Schölkopf B, Schöls L, Grosse-Wentrup M. A cognitive brain-computer interface for patients with amyotrophic lateral sclerosis. Prog Brain Res. 2016;228:221-39.

[44] Sollfrank T, Ramsay A, Perdikis S, Williamson J, Murray-Smith R, Leeb R, Millán JDR, Kübler A. The effect of multimodal and enriched feedback on SMRBCI performance. Clin Neurophysiol. 2016;127(1):490-98.

[45]Chang MH, Lee JS, Heo J, et al. Eliciting dual-frequency SSVEP using a hybrid SSVEP-P300 BCI. J Neurosci Methods. 2016;258:104-13.

[46] Ma T, Li H, Yang H, Lv X, Li P, Liu T, Yao $\mathrm{D}, \mathrm{Xu} \mathrm{P}$. The extraction of motion-onset VEP BCI features based on deep learning and compressed sensing. J Neurosci Methods. 2017;275:80-92.

[47] Göksu H. BCI oriented EEG analysis using $\log$ energy entropy of wavelet packets.
Biomed Signal Process Control. 2018;44:101-109. 